\title{
A Sensitive Period for the Impact of Hearing Loss on Auditory Perception
}

\author{
Bradley N. Buran, ${ }^{1}$ Emma C. Sarro, ${ }^{1}$ Francis A. M. Manno, ${ }^{1}$ Ramanjot Kang, ${ }^{1}$ Melissa L. Caras, ${ }^{1}$ and Dan H. Sanes ${ }^{1,2}$ \\ ${ }^{1}$ Center for Neural Science and ${ }^{2}$ Department of Biology, New York University, New York, New York 10003
}

\begin{abstract}
Manipulations of the sensory environment typically induce greater changes to the developing nervous system than they do in adulthood. The relevance of these neural changes can be evaluated by examining the age-dependent effects of sensory experience on quantitative measures of perception. Here, we measured frequency modulation (FM) detection thresholds in adult gerbils and investigated whether diminished auditory experience during development or in adulthood influenced perceptual performance. Bilateral conductive hearing loss $(\mathrm{CHL})$ of $\approx 30 \mathrm{~dB}$ was induced either at postnatal day 10 or after sexual maturation. All animals were then trained as adults to detect a $5 \mathrm{~Hz}$ FM embedded in a continuous $4 \mathrm{kHz}$ tone. FM detection thresholds were defined as the minimum deviation from the carrier frequency that the animal could reliably detect. Normal-hearing animals displayed FM thresholds of $25 \mathrm{~Hz}$. Inducing CHL, either in juvenile or adult animals, led to a deficit in FM detection. However, this deficit was greater for juvenile onset hearing loss $(89 \mathrm{~Hz})$ relative to adult onset hearing loss $(64 \mathrm{~Hz})$. The effects could not be attributed to sensation level, nor were they correlated with proxies for attention. The thresholds displayed by CHL animals were correlated with shallower psychometric function slopes, suggesting that hearing loss was associated with greater variance of the decision variable, consistent with increased internal noise. The results show that decreased auditory experience has a greater impact on perceptual skills when initiated at an early age and raises the possibility that altered development of CNS synapses may play a causative role.
\end{abstract}

Key words: critical period; deafness; frequency discrimination; temporal processing

\section{Introduction}

The influence of sensory experience on neural structure and function varies with age. Loss of peripheral sensory activity has a greater impact when it occurs during developmental sensitive periods. Interventions that restore activity (e.g., cochlear prostheses) during these epochs are associated with better recovery of neural function (Ponton and Eggermont, 2001; Keuroghlian and Knudsen, 2007; Espinosa and Stryker, 2012; Kral and Sharma, 2012). However, the onset and duration of sensitive periods during which neural function is vulnerable to sensory deprivation depends on the specific property (Hooks and Chen, 2007; de Villers-Sidani and Merzenich, 2011; Erzurumlu and Gaspar, 2012). Therefore, if neural-sensitive periods for sensory deprivation are a reliable proxy for perception, then behavioral measures should display a strong dependence on the deprivation age of onset. Here, we tested this principle by measuring perceptual performance in gerbils that were reared with hearing loss or that acquired the same hearing loss in adulthood.

Received Feb. 11, 2013; revised Dec. 2, 2013; accepted Jan. 3, 2014.

Author contributions: B.N.B., E.C.S., F.A.M.M., R.K., and D.H.S. designed research; B.N.B., E.C.S., F.A.M.M., R.K., and M.L.C. performed research; B.N.B. contributed unpublished reagents/analytic tools; B.N.B., E.C.S., F.A.M.M., R.K., M.L.C., and D.H.S. analyzed data; B.N.B. and D.H.S. wrote the paper.

This work was supported by the National Institutes of Health (Grant DCO09237 to D.H.S.). We thank Antje Ihlefeld for helpful discussions and comments on the manuscript.

The authors declare no competing financial interests.

Correspondence should be addressed to Dan H. Sanes, Center for Neural Science, New York University, 4 Washington Place, New York, NY 10003. E-mail: dhs1@nyu.edu.

DOI:10.1523/JNEUROSCI.0647-13.2014

Copyright $\odot 2014$ the authors $\quad 0270-6474 / 14 / 342276-09 \$ 15.00 / 0$
Auditory perceptual deficits are commonly attributed to peripheral dysfunction because inner ear damage disrupts cochlear processing (Oxenham and Bacon, 2003). However, prolonged periods of conductive hearing loss (CHL) due to chronic otitis media may also induce perceptual deficits (Whitton and Polley, 2011). In fact, the central encoding of spatial location is profoundly altered by unilateral CHL and these functional changes can account for impaired perceptual abilities (Clements and Kelly, 1978; Knudsen et al., 1984a, 1984b; Wilmington et al., 1994; Moore et al., 1999; Parsons et al., 1999; King et al., 2000; Popescu and Polley, 2010). Furthermore, direct measures from auditory cortex demonstrate that CHL induced at the time of ear canal opening disrupts synapse function, but not when induced in adulthood (Takesian et al., 2012). Therefore, we investigated the perceptual consequence of bilateral CHL because this form of hearing loss produces air-conducted sound attenuation but does not raise bone-conducted thresholds, indicating no cochlear damage (Tucci et al., 1999).

To evaluate a sensitive period for perceptual maturation, we measured frequency modulation (FM) detection, a fundamental property of communication sounds, including speech (Singh and Theunissen, 2003). Because this percept matures slowly (Banai et al., 2011), we reasoned that it would remain vulnerable to deprivation during development. Indeed, children and adults with sensorineural hearing loss display poorer FM detection thresholds (Moore and Skrodzka, 2002; Buss et al., 2004; Halliday and Bishop, 2006). Because there is evidence both for neural sensitive periods and neural consequences of adult-onset hearing loss 
(Syka, 2002; de Villers-Sidani and Merzenich, 2011; Kral and Sharma, 2012), we controlled for the onset age, magnitude, and duration of CHL. Our findings reveal that FM detection thresholds were impaired by hearing loss in both young and adult animals, but the effect was more severe when hearing loss onset occurred during development.

\section{Materials and Methods}

Animals and groups. Behavioral data were obtained from adult Mongolian gerbils (Meriones unguiculates) divided into three treatment groups: normal-hearing gerbils (control adult, $n=16$ of either sex), gerbils with CHL induced in adulthood (adult CHL, $n=23$ of either sex), and gerbils with CHL induced before ear canal opening (postnatal day 10 [P10] CHL, $n=17$ of either sex). All groups were trained and tested on the behavioral task as adults ( $\geq$ P70). Two adult CHL and one P10 CHL gerbil were excluded from the study because they failed to learn the task after 10 sessions. An additional adult CHL was removed from the study after it developed an infection. All animals were weaned at the same age, housed in our animal colony, and trained and tested under the same conditions.

Three cohorts comprised the P10 CHL group and were deprived before ear canal opening. Two of these cohorts were tested as young adults at $\approx \mathrm{P} 90$ (i.e., after $80 \mathrm{~d}$ of deprivation). To determine whether duration of deprivation has an impact on FM depth perception, one cohort was tested after 1 year of CHL. Because there was no statistically significant difference in the variance of log-transformed FM thresholds (Levene's test, $p=0.36, \mathrm{df}=1, F=0.89$ ) or mean FM threshold (Welch's twosample $t$ test, $t=0.24, \mathrm{df}=13.24, p=0.81$ ) between those tested as young adults and those tested after 1 year of sensory deprivation, we pooled the data for all subsequent analyses.

The initial experiment for testing the effect of acute sensory deprivation on FM detection in adults (i.e., the adult CHL group) used six gerbils of either sex that had prior experience on the task as normal-hearing adults. The second and third cohorts of this group (six gerbils each of either sex) had no prior experience at the time of training and testing. In the first three cohorts, all animals were tested after $14-30 \mathrm{~d}$ of sensory deprivation. To determine whether duration of deprivation has an impact on FM depth perception, an additional adult cohort (five gerbils of either sex) was tested after $80 \mathrm{~d}$ of sensory deprivation, similar to the P10 CHL group (see Fig. 2C, orange diamonds). We found no statistically significant difference in the variance of log-transformed FM thresholds (Bartlett's test, $T=2.46, p=0.29$ ) or mean FM threshold (one-way ANOVA, $F=1.15, p=0.33$ ) between these three subgroups (i.e., trained adult $\mathrm{CHL}$, acute adult $\mathrm{CHL}$, and aged acute $\mathrm{CHL}$ ). Therefore, we treated all adult-onset $\mathrm{CHL}$ animals as a single group for all subsequent analyses.

Surgery for CHL. Bilateral CHL was induced before ear canal opening (P10) for the P10 group or after sexual maturation (P83) for the adult CHL group. Short-term surgical analgesia was induced using methoxyflurane (Medical Developments International) and the malleus removed through a perforation in the tympanic membrane (Tucci et al., 1999; Rosen et al., 2012). This procedure induces an attenuation of $\approx 55 \mathrm{~dB}$ at $4 \mathrm{kHz}$, as assessed by auditory brainstem response (Tucci et al., 1999; Rosen et al., 2012). However, behavioral measures obtained in the present study indicate an attenuation of $\approx 30 \mathrm{~dB}$ at $4 \mathrm{kHz}$ (see Results).

Behavioral assessment. Animals were placed on controlled water access and trained to drink from a lick spout in the testing cage. Figure 1 illustrates the stimulus waveform and trial structure of the behavioral procedure. All animals were trained to detect a $1 \mathrm{~s}, 5 \mathrm{~Hz}$ sinusoidal FM embedded in a continuous $4 \mathrm{kHz}$ tone carrier at $45 \mathrm{~dB}$ SPL (normalhearing controls) or $95 \mathrm{~dB}$ SPL (P10 CHL and adult CHL groups) to compensate for the elevated thresholds. Task difficulty was adjusted by controlling the maximum deviation of the modulation (FM depth) from the carrier frequency (Fig. 1). The FM cue was followed by a mild aversive stimulus (300 ms electrical shock) delivered via the metal lick spout (Heffner and Heffner, 1995; Kelly et al., 2006; Sarro and Sanes, 2010; Rosen et al., 2012). Within a few sessions, animals learned to avoid the shock by breaking contact with the lick spout when they detected the FM

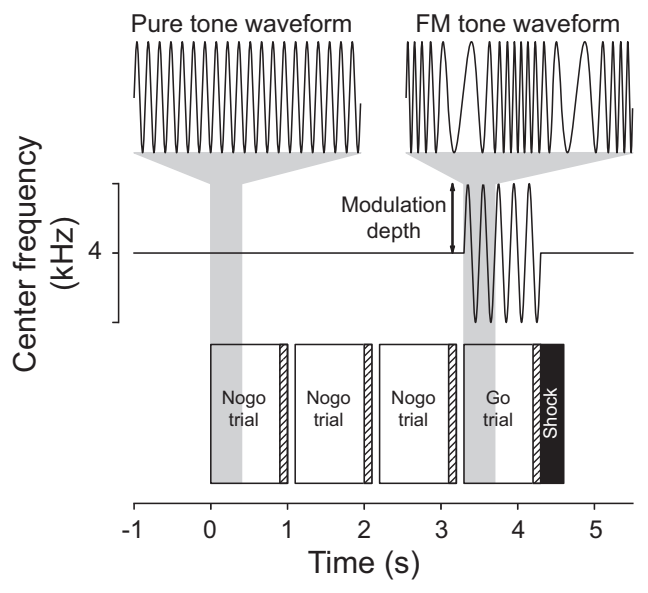

Figure 1. Overview of FM detection task. The target (a sinusoidally frequency modulated tone) is embedded in a continuous $4 \mathrm{kHz}$ carrier at a rate of $5 \mathrm{~Hz}$. Task difficulty was modulated by adjusting the maximum frequency deviation from $4 \mathrm{kHz}$ (arrow, modulation depth). Examples of the fine structure for a pure and FM tone waveform are shown above the center frequency plot. Trials, each lasting $1 \mathrm{~s}$, were presented at a rate of $\sim 1 / \mathrm{s}$ while the animal was drinking from the water spout. Three to five no go trials were delivered between each go trial. Trials were suspended when animals broke contact with the spout for $>50 \mathrm{~ms}$. To determine whether the animal detected the target, spout contact was monitored during the last $100 \mathrm{~ms}$ of each trial (cross-hatched region) and scored as a "yes" response if they were off the spout for at least $50 \mathrm{~ms}$. A 300 ms aversive stimulus followed each go trial (black). Middle and bottom images are shown on the same timescale; the temporal relationship of the fine structure examples in the top image are indicated by the gray background.

cue. Go (i.e., FM) and no go (i.e., no modulation) trials were scored by determining whether the animal broke contact with the spout for at least $50 \mathrm{~ms}$ during the last $100 \mathrm{~ms}$ of the trial period (Fig. 1). Breaking contact with the spout for $\geq 50 \mathrm{~ms}$ was scored as a hit on go trials and as a false alarm on no go trials.

The first few sessions consisted of procedural training during which a series of go trials consisting of $500 \mathrm{~Hz}$ FM depth were presented by the experimenter until the gerbils responded correctly on at least 7 out of 10 consecutive go trials. Once this criterion was reached, we tested animals on a range of at least 5 FM depths within each session, presented in descending order from largest to smallest. An animal's performance on the previous session determined the range of depths on which it was tested during the following session (i.e., always bracketing the previous threshold). Three to 5 no go trials were delivered in between each go trial, randomized to avoid temporal conditioning. Because animals display between-subject variability in pain sensitivity (Mogil, 1999), we adjusted the shock level for each animal to reliably produce withdrawal from the spout, but not so great as to dissuade the animal from approaching the spout on subsequent trials. The shock was turned off for the two hardest FM depths being assessed in the series. Our logic was that animals performing a near-threshold detection task could easily fail to detect the conditioned stimulus. If so, the unconditioned stimulus would effectively train animals to avoid the water spout entirely or adopt a strategy that is associated with a high false alarm rate (e.g., pecking at the water spout).

However, this paradigm could have differentially conditioned the animals to respond only to the reinforced FM depths, but not unreinforced depths (Wagner and Rescorla, 1972; LoLordo and Fairless, 1985). Although there are many factors in our study that differ from standard differential conditioning paradigms (e.g., the use of smaller FM depths on successive days), we performed a control experiment to determine whether the lack of negative reinforcement for all depths led to artificially elevated FM thresholds. Five normal-hearing gerbils were run on the paradigm described above, except the shock was delivered for all FM depths. These animals displayed an average FM depth threshold of 94 (SD 33$) \mathrm{Hz}\left(\log _{10} \mathrm{~Hz}=1.95\right.$, SD 0.13$)$. This performance was significantly poorer than that observed in normal hearing controls that did not have reinforcement at the hardest FM depths. 
Tone thresholds were determined using the same behavioral procedure described for FM threshold assessment. A $1 \mathrm{~s}$ tone $\left(2.5 \mathrm{~ms} \cos ^{2}\right.$ onset/offset envelope) was used for the go trials with silence during the no go and intertrial periods. Tone level was varied in $5 \mathrm{~dB}$ steps and the animal's threshold performance on the previous session determined the range of levels on which it was tested during the next session (i.e., always bracketing the previous threshold). Because we only tested tone thresholds for three to five sessions, the session with the best threshold was selected as the animal's threshold. Two of the control adults tested did not perform a sufficient number of trials to assess their tone thresholds and were removed from the analysis of sensation level.

Experiment setup. Gerbils were placed in a small cage within an acoustic isolation booth and observed in a separate room via a closed circuit monitor. The test cage contained a stainless steel drinking spout and metal floor plate that formed the terminals of a circuit through which a mild aversive shock could be delivered at the end of warning trials (Sarro and Sanes, 2010). Spout contact was monitored via a custom-built circuit that used a $940 \mathrm{~nm}$ infrared LED (LTE 302; Lite-On) and photodiode (OP950; Optek Technology) contained in custom housing (Techwell Solutions). This circuit could also be used to deliver a mild aversive shock at the end of warning trials. Stimuli were digitally generated using a real-time processor (RZ6; Tucker-Davis Technologies) and delivered via a single free-field speaker (DX25TG05-04; Vifa) positioned $1 \mathrm{~m}$ in front of the lick spout. The speaker was calibrated using a spectrum analyzer (Brüel and Kjær) via a $1 / 4$ inch free-field condenser microphone (Brüel and Kjær) positioned $1 \mathrm{~cm}$ above the spout.

Data analysis. Percent yes (i.e., similar to percent correct except the no go value is included) functions from sessions consisting of at least five presentations of five different depths were fitted using the open-source package psignifit. This package can fit several different psychometric functions and allows the specification of prior probability distributions for each parameter (e.g., guessing and lapsing rate). For this study, a psychometric function representing a linear transform of stimulus intensity values (i.e., the "mw0.1" core available in the bootstrap inference algorithm) fitted by a right gumbel sigmoid produced a reasonable fit to most of our data. The function is described as follows:

$\Psi(x ; m, w, y, \lambda)=\gamma+(1-\gamma-\lambda)$

$$
F(x ; m, w)
$$

where:

$$
F(x ; m, w)=\exp \left(-\exp \left(-\frac{z(\delta)-z(1-\delta)}{w}(x-m)-z(0.5)\right)\right)
$$

and:

$$
z(\delta)=\log (-\log (\delta)) .
$$

Here, $x$ represents stimulus difficulty, $m$ the midpoint, $w$ the width of the interval over which $F(x ; m, w)$ rises from $\delta$ to $1-\delta$ (in psignifit's documentation, $\delta$ is referred to as $\alpha$; however, we use $\delta$ to differentiate it from the $\alpha$ parameter of the beta prior described below), $\lambda$ is the lapse rate, and $\gamma$ is the FA rate. Both $m$ and $w$ were unconstrained and $\delta$ was fixed at 0.1 (the default value set by psignifit). The prior distribution for the FA rate, $\gamma$, was specified as a beta distribution with the mode fixed at
B

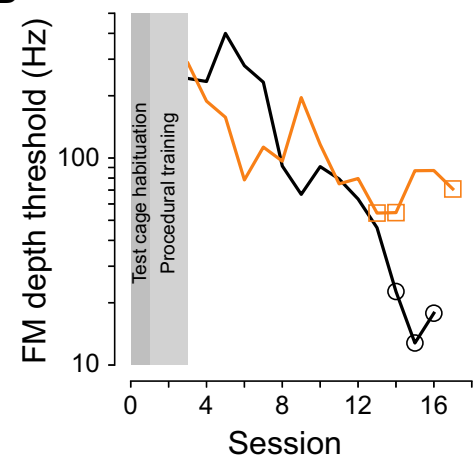

D

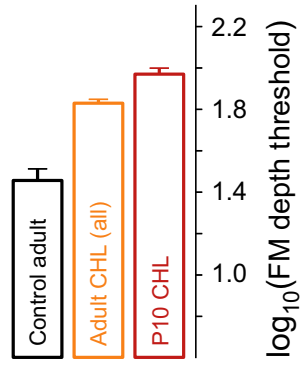

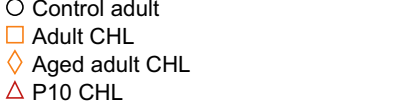

$\square$ Adult $\mathrm{CHL}$
$\triangle$ Aged adult $\mathrm{CHL}$
$\triangle \mathrm{P} 10 \mathrm{CHL}$

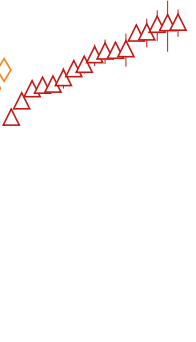

눙

$\frac{1}{20}$

FM depth detection thresholds were worse in animals with CHL. $\boldsymbol{A}$, Example psychometric functions from a single test (black) and P10 CHL (red) animal. FM depth threshold was estimated by fitting a psychometric function (solid (black) and adult CHL animal (orange). The first session was devoted to test indicate \pm SEM. The aged adult CHL group is plotted separately (diamond marker). In all other panels and figures, the aged adult CHL group was combined with the adult CHL group. D, Average FM depth threshold for each group. Bars indicate \pm SEM.

the empirical FA rate for that session by setting the distribution parameters, $\alpha$ and $\beta$, to $N_{\mathrm{FA}}+1$ and $N_{\mathrm{CR}}+1$. Following guidelines described in Fründ, Haenel and Wichmann (2011), the prior for the lapsing rate, $\lambda$, was set to a mode of 0.05 (i.e., $\alpha=1.5, \beta=12$ ). These prior distributions allowed us to specify the most likely value for the guess rate based on our empirical observations.

As illustrated in Figure $2 A$, fitted functions were transformed to a $d^{\prime}$ metric, defined as $Z$ (hit fraction) $-Z$ (FA fraction), which normalizes performance relative to the FA rate for a given session. Threshold was defined as the FM depth at which performance reached a $d^{\prime}$ of 1 . To ensure that fits were of sufficient quality, we discarded fits in which the deviance of the fit to the original dataset exceeded the $95^{\text {th }}$ percentile of the deviance of the fit to 1000 simulated datasets (for details, see Fründ et al., 2011).

Because animal behavior can be variable from session to session due to various factors (e.g., motivation, attention, confidence in the task), we considered several approaches to estimating the psychometric threshold of each animal. One straightforward approach is to calculate the asymptotic threshold (e.g., the average of the last three sessions) regardless of how well the animal was performing over these sessions. However, this approach could give greater weight to poor performance that reflected behavioral, rather than sensory, factors. An alternate approach is to select the three sessions with the best FM depth thresholds after a specific training period (markers in Fig. 2B). The average of the three best thresholds were generally better than the average threshold over the final $3 \mathrm{~d}$ of testing (data not shown), suggesting that some animals lost motivation in the task toward the end of the experiment. Regardless of the approach for selecting the three sessions to average, a single-factor ANOVA test reports similar levels of significance when comparing the treatment groups on the various parameters tested (e.g., FM depth threshold, FA rate, lapse rate, psychometric slope, etc.). Because the choice of assessing psycho- 
metric threshold did not affect the final outcome-that is, the statistical significance of between-group differences—-subsequent analysis focuses on the three best sessions from each animal.

Statistical tests were first performed to determine whether the dependent variable was normally distributed for each treatment group (control, adult CHL, P10 CHL), using a Shapiro-Wilk normality test. Although there were only five departures from normality out of $21 \mathrm{com}-$ binations (slope of psychometric function and FA rate for adult CHL animals, $p<0.0001$ and $p=0.0006$, respectively; sensation level for P10 CHL, $p=0.02$; slope of psychometric function and lapsing rate for control adults, $p=0.02$ and $p=0.03$, respectively), we used Levene's test for equal variance (using the median value as an estimate of each group's center) because it is more robust when samples deviate from a normal distribution. Of all of the dependent variables tested, only 2 had unequal variance (FM thresholds, $\mathrm{df}=2, F$-value $=8.99, p=0.0004$; slope of psychometric function, $\mathrm{df}=2, F$-value $=7.74, p=0.001$ ). For all multiple-comparison tests, we used the nonparametric Kruskal-Wallis test followed by pairwise comparisons using a two-sided Wilcoxon test with Holm-corrected $p$-values.

The statistical significance of the correlation, $\rho$, between variables was assessed by randomly shuffling the original dataset and computing the correlation statistic on this shuffled set. This process was repeated at least 10,000 times to generate a reference distribution, $\rho^{*}$, and the two-sided $p$-value was computed as the fraction of the distribution that exceeded the actual statistic as follows:

$$
\frac{\sum_{n=1000}\left|\rho^{\star}\right| \geq|\rho|}{n}
$$

\section{Results}

\section{CHL impairs detection of frequency modulation}

To evaluate the FM detection thresholds as a function of hearing status, psychometric functions were obtained from three groups of adult gerbils (see Materials and Methods): adults with normalhearing $(n=16)$, adults raised with CHL induced at P10 $(n=$ $17)$, and adults with CHL induced at P83 $(n=23)$. On average, normal-hearing adult gerbils displayed FM depth thresholds of $25(\mathrm{SD} 16) \mathrm{Hz}\left(\log _{10} \mathrm{~Hz}=1.31, \mathrm{SD} 0.27\right)$. This value suggests that FM detection is superior to chinchillas $(\approx 100 \mathrm{~Hz}$; Long and Clark, 1984) and close to normal-hearing humans $(\approx 10 \mathrm{~Hz}$; Shower and Biddulph, 1931; $\approx 20 \mathrm{~Hz}$; Sek, 1994).

In contrast to controls, both adult CHL and P10 CHL animals displayed poorer detection thresholds of 64 (SD 15) $\mathrm{Hz}$ $\left(\log _{10} \mathrm{~Hz}=1.80, \mathrm{SD} 0.10\right)$ and $89(\mathrm{SD} 27) \mathrm{Hz}\left(\log _{10} \mathrm{~Hz}=1.93, \mathrm{SD}\right.$ $0.14)$, respectively. There was a large range of FM thresholds with a degree of overlap between groups (Fig. 2 C). The best adult CHL animals displayed performance on par with that of the worst normal-hearing controls. Likewise, the best half of the P10 CHL animals had performance comparable to the worst half of the adult CHL group. To test for significance, FM depth thresholds were converted to $\log _{10}$ values because this is the likely decision variable for frequency discrimination (Demany and Semal, 1989; Moore and Sek, 1996). A Kruskal-Wallis test reported a main effect of group $\left(\chi^{2}=34.5, \mathrm{df}=2, p<0.0001\right)$. A Wilcoxon test using Holm-corrected $p$-values demonstrated significant differences between each group pair (control vs adult CHL: $\mathrm{df}=1, p<$ 0.0001; control vs P10 CHL: $\mathrm{df}=1, p<0.0001$; P10 CHL vs adult CHL: $\mathrm{df}=1, p=0.0008)$. Therefore, CHL impairs performance regardless of age of onset, but the impairment is greater when hearing loss is induced during early development (Fig. 2D).

To determine whether CHL resulted in a general decrease in sensitivity to differences in stimulus magnitude, the slope of the psychometric function at $d^{\prime}=1$ was measured for the three best sessions. As shown in Figure 3, the average psychometric function slope was shallower in animals with $\mathrm{CHL}$ whether induced at

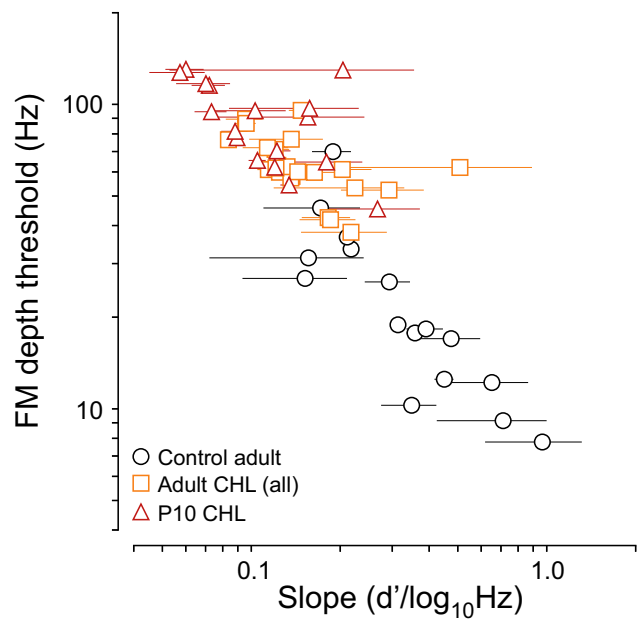

Figure 3. Psychometric function slopes were shallower and performance was more variable for animals with CHL. Each animal's FM psychometric function slope, $d^{\prime} / \log _{10}(\mathrm{~Hz})$, is plotted against the FM detection threshold. The psychometric function slopes were steepest for control animals. Furthermore, there was a significant correlation between threshold and slope for all animals. Values were obtained from the psychometric functions with the three best FM depth threshold values, as described in Figure $2 B$. Error bars indicate \pm SEM.

P10 or in adulthood. A Kruskal-Wallis test reported a main effect of group $\left(\chi^{2}=25.6, \mathrm{df}=2, p<0.0001\right)$. A Wilcoxon test using Holm-corrected $p$-values was performed on group pairs and demonstrated significant differences between each (control vs adult CHL: $\mathrm{df}=1, p<0.0001$; control vs P10 CHL: $\mathrm{df}=1, p<$ 0.0001; P10 CHL vs adult CHL: $\mathrm{df}=1, p=0.03$ ). In addition, there was a strong negative correlation between FM detection threshold and slope (Spearman's rank correlation, $\rho=-0.79$; permutation test, $p<0.0001)$. This result suggests that normal hearing animals could discriminate smaller stimulus differences (i.e., steep slope) compared with CHL animals (i.e., very shallow slope).

\section{Poorer FM detection is not explained by sensation level or task performance}

Human psychophysical data suggest that FM detection improves with increasing sensation level (i.e., loudness of the signal relative to the subject's threshold). To investigate whether this could explain the impaired performance in CHL animals, we assessed 4 $\mathrm{kHz}$ tone behavioral thresholds after completion of the FM detection testing in all but six normal-hearing adults to determine the sensation level at which each animal performed the FM detection task. The absolute thresholds for the three groups were 28.2 (SD 12.2) dB SPL for controls, 59.4 (SD 11.2) dB SPL for P10 CHL animals, and 56.3 (SD 10.2) dB SPL for adult CHL animals. This demonstrates that the CHL procedure introduces a $30 \mathrm{~dB}$ hearing loss regardless of age of onset and translates to an average sensation level of 19.9 (SD 7.1) dB for control adults, 33.4 (SD 12.7) $\mathrm{dB}$ for $\mathrm{P} 10 \mathrm{CHL}$, and 36.4 (SD 11.6) $\mathrm{dB}$ for adult CHL animals (Fig. 4A). A Kruskal-Wallis test reported a significant effect of group $\left(\chi^{2}=12.0, \mathrm{df}=2, p=0.002\right)$. However, a post hoc Wilcoxon test using Holm-corrected $p$-values revealed no significant difference between P10 and adult CHL animals ( $p=0.48$ ), indicating that $\mathrm{CHL}$ induced a similar level of attenuation in both groups. In contrast, the control adults were run at a lower sensation level relative to both the $\mathrm{P} 10(p=0.03)$ and adult CHL $(p=$ 0.001 ) groups. This indicates that, if anything, the CHL animals had an advantage in terms of sound level and that sensation level was not a factor that could explain the impaired performance. 
If CHL animals performed poorly on FM detection regardless of stimulus difficulty, then the elevated thresholds could reflect a general cognitive problem in performing the behavioral task. To investigate whether the within-group variance and cross-group differences could be explained by poor task performance, we examined four performance metrics: false alarm rate, lapsing rate (i.e., miss on easy trials), sensitivity at the easiest FM depth, and reaction time. The results of these analyses suggest that there were no systematic between-group differences in performance that could explain the differences in FM detection thresholds.

FA rate (the probability of an incorrect response when the signal is not presented) is influenced in part by the animal's decision process (i.e., the criterion or threshold above which they will produce a "yes" response). This decision process, in turn, is influenced by various factors, including the shock level and task difficulty. Therefore, systematic differences in FA rate between groups may suggest that we failed to treat these groups equally in adjusting the aversive stimulus or selecting the appropriate sequence of values to test them on each day. With the exception of one animal, the majority of CHL animals had FA rates comparable to those of the control adult group (Fig. 4B). In fact, the animals with the highest and lowest FM thresholds had the lowest FA rates (data not shown) and there was no correlation between FM threshold and FA rate (permutation test using Spearman's rankorder, $p=0.71)$. A Kruskal-Wallis test reported no effect of group $\left(\chi^{2}=1.8, \mathrm{df}=2, p=0.41\right)$. Therefore, it is unlikely that dissimilarities in the testing procedure could explain the group differences in FM detection threshold.

Lapsing rate (the probability of an incorrect response independent of stimulus intensity) has been used as a proxy for attention. This rate reflects the upper asymptote of the psychometric function, placing an upper bound (1-lapsing rate) on the maximum fraction correct the animal can be expected to achieve regardless of stimulus intensity. Inattentive animals would tend to miss particularly easy FM depths, resulting in a higher lapsing rate. Here, performance on the easiest FM depth in each session was used as a means of estimating lapsing rate. There was no systematic relationship between lapsing rate and FM thresholds (permutation test using Spearman's rank-order, $p=0.21$ ), nor was there a significant difference between groups (Fig. $4 C$; Kruskal-Wallis, $\left.\chi^{2}=4.8, \mathrm{df}=2, p=0.09\right)$. Post hoc pairwise comparisons revealed no significant differences between groups. A related measure of performance is sensitivity $\left(d^{\prime}\right)$ at asymptotic performance. Although there was no systematic relationship between $d^{\prime}$ at the easiest stimulus depth and FM thresholds (permutation test using Spearman's rank-order, $p=0.69$ ), there was a modest difference between group (Kruskal-Wallis, $\chi^{2}=5.9, \mathrm{df}=2$, $p=0.05)$, with CHL groups displaying slightly better asymptotic sensitivity (Fig. 4D). Post hoc pairwise comparisons revealed no significant differences between groups. We also investigated the estimate of lapsing rate and $d^{\prime}$ at asymptotic performance using our fitted data and found no significantbetween-group differences(Kruskal-
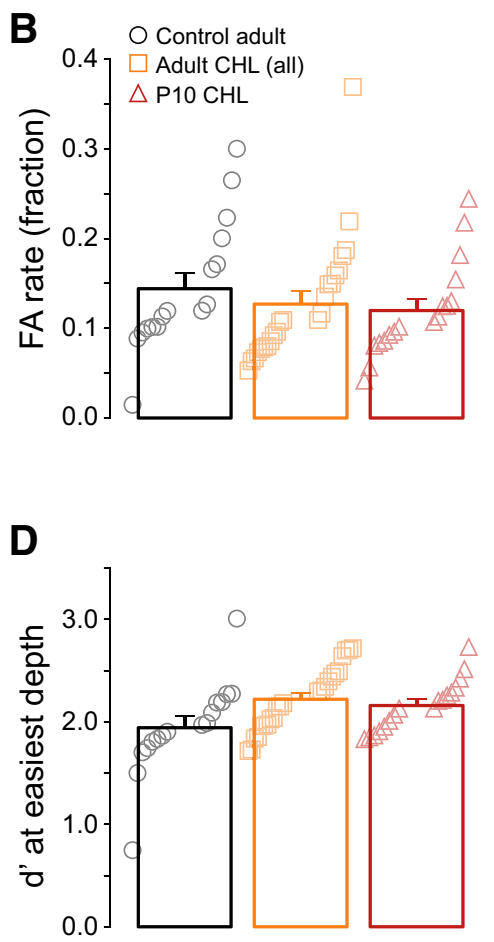

Figure 4. The FM depth detection thresholds were not correlated with sensation level $(\boldsymbol{A})$ and there was no between-group difference for FA rate $(\boldsymbol{B})$, lapse rate on the easiest FM depth $(\boldsymbol{C})$, or sensitivity at the easiest stimulus depth $(\boldsymbol{D})$. Data presented in all plots are averaged from the animal's three best sessions, as described in Figure $2 B$. Error bars indicate SEM.

Wallis) or systematic relationship between lapsing rate and FM thresholds (permutation test using Spearman's rank-order).

Reaction time has been associated with task difficulty, sustained attention or vigilance, and the speed-accuracy trade-off (Cattell, 1886; Saltzman and Garner, 1948; Buck, 1966; Luce and Green, 1972; Teichner and Krebs, 1972; Weissberg et al., 1990; Salthouse and Hedden, 2002). Although the meaning of reaction time with respect to the behavioral procedure is subject to interpretation, it was used as a quantitative measure of performance to further establish the lack of behavioral differences between the groups. The probability of spout contact was calculated as a function of trial duration for all "hit" responses near each animal's FM detection threshold. Because animals typically do not return to the spout until after the trial is over, this measure can be interpreted as the cumulative distribution function of reaction time (e.g., the cumulative probability that the animal will have responded by a certain point in time). Steeper slopes indicate that the animal has a tendency to respond around a certain point in time, whereas slopes closer to unity indicate that reaction times are uniformly distributed throughout the trial. As shown in Figure $5 A$, there were no group differences in the probably of spout contact during threshold go trials. Similarly, there were no group differences for miss trials (Fig. 5A). For all groups, the probability of being off the spout on threshold go trials increased by 0.1 for every $100 \mathrm{~ms}$ increment of stimulus after the first $300 \mathrm{~ms}$.

To obtain a single reaction time value for each animal, we measured the average time at which the animal first leaves the spout on go trials that were scored as a "hit," even if the animal returned briefly to the spout later in the trial (this eventuality is illustrated in Fig. $5 A$ for the hit trials; there is a marginal increase in probability of being on the spout after $950 \mathrm{~ms}$ ). As shown in Figure $5 B$, the mean reaction time for suprathreshold values is $\approx 515 \mathrm{~ms}$ across all treatment groups with no significant group 
A

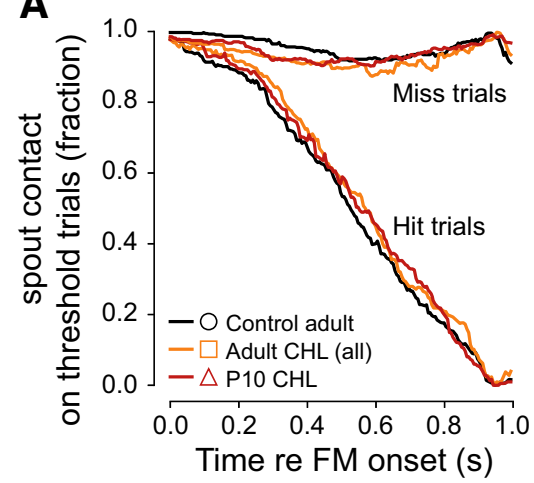

Figure 5. Reaction time was nearly identical across control and CHL groups. A, Average probability of spout contact relative to onset of frequency modulation is shown for hit trials near the animals' threshold. For reference, spout contact on miss trials are plotted as well. Although we required the animal to be on the spout before presenting a trial, there is a non-negligible chance of the animal leaving the spout just before the trial begins. Even though the animal may have been off the spout by the end of some miss trials, it was not scored as a hit because it did not meet the criterion of being off the spout for at least $50 \mathrm{~ms}$. $\boldsymbol{B}$, Reaction time for individual trials was computed as the time at which the animal first left the spout regardless of whether they chose to return to the spout. Reaction time at threshold was not correlated with the animal's FM depth threshold and there were no between-group differences. Error bars indicate \pm SEM.

differences (Kruskal-Wallis, $\chi^{2}=1.76, \mathrm{df}=2, p=0.41$ ) and is not correlated with FM threshold (permutation test using Spearman's rank-order, $p=0.44$ ). The consistent betweengroup performance on these four metrics indicates that the animals in each treatment group performed the FM detection task in a nearly identical manner.

\section{Discussion}

The neural consequences of altered sensory experience are most profound during development, often referred to as sensitive periods. For example, when cochlear prostheses are implanted in deaf subjects during the first 18 postnatal months, they achieve better cortical activation compared with subjects implanted at a later age (Ponton and Eggermont, 2001; Sharma et al., 2002; Kral and Sharma, 2012). These neurophysiological outcomes are consistent with behavioral data that demonstrate better speech production and language acquisition in subjects who receive implants at a younger age (Svirsky et al., 2004; Niparko et al., 2010). Similarly, clinical studies on visual deprivation (e.g., cataracts) suggest the existence of multiple sensitive periods (Lewis and Maurer, 2005; Scheiman et al., 2005).

Despite firm evidence for sensitive periods, hearing lossinduced changes to central auditory function are also well documented in adulthood, especially during senescence (Syka, 2002, 2010; Chisolm et al., 2003; Caspary et al., 2008; Turner et al., 2013). Regardless of age of onset, both short- and long-term auditory deprivation are associated with measurable changes in sensory and cognitive function (Moore et al., 1996; Formby et al., 2003; Munro and Blount, 2009; Lin et al., 2011; Seldran et al., 2011; Humes et al., 2012). Similarly, environmental manipulations that provide supplemental sound exposure suggest that some forms of plasticity are present in adulthood (Pienkowski and Eggermont, 2011). Therefore, this study was designed to determine whether an auditory percept, FM detection, was affected by the same CHL manipulation induced either before neural and behavioral properties are mature (P10, ear canal opening) or after they reach an adult state (P83). The results demonstrate that CHL induced at either age leads to poorer FM detection. However, the effect was larger when CHL was induced during early development.

\section{Age-dependent effect of hearing loss onset}

If the neural properties that are impaired by hearing loss during a sensitive period are causally related to auditory perception, then juvenile onset hearing loss would have a greater impact on perception than the same manipulation commencing in adulthood. To test this idea, we induced CHL via bilateral malleus removal. This form of $\mathrm{CHL}$ raises air conduction thresholds, but not bone conduction thresholds, indicating that there is no damage to the cochlea (Tucci et al., 1999). This minimized the potential contribution of cochlear processing deficits (Oxenham and Bacon, 2003). In fact, children with chronic otitis media often experience transient hearing loss without damage to the cochlea and this deprivation is thought to impair neural and perceptual development (Whitton and Polley, 2011). Furthermore, unilateral CHL during development can impair binaural processing and speech detection in noise (Clements and Kelly, 1978; Knudsen et al., 1984a, 1984b; Moore et al., 1999; Parsons et al., 1999; King et al., 2000). Longer durations of unilateral CHL, due to the congenital absence of an ear canal, are associated with a poorer ability to understand speech in the presence of noise after corrective surgery, suggesting termination of the sensitive period for recovery (Gray et al., 2009).

Given an equivalent elevation of hearing thresholds, the animals that experienced CHL from the age of ear canal opening displayed poorer FM detection relative to animals that experienced CHL beginning in adulthood (Figs. 2, 3). Because measures of audibility and proxies for nonsensory factors showed no difference between the CHL groups, these results indicate that the developing nervous system is more vulnerable to the manipulation. However, the noteworthy finding is that adult onset hearing loss led to a significant impairment of FM detection. This result is consistent with a human study in which a similar carrier and modulation frequency were tested, yielding FM detection thresholds $<16 \mathrm{~Hz}$ for control subjects and $\approx 90 \mathrm{~Hz}$ for elderly subjects with moderate hearing loss (Moore and Skrodzka, 2002). These results imply that the neural properties used to define a sensitive period are not exclusive correlates for a specific perceptual deficit.

\section{Alternative explanations for the effect of CHL}

One explanation for the results could be that the signals were not sufficiently audible to animals with CHL. However, $4 \mathrm{kHz}$ behavioral thresholds did not differ between CHL groups and stimuli were usually delivered at a higher sensation level for CHL animal (Fig. 4A). It is also possible that nonsensory factors such as attention contributed to the poorer FM detection thresholds displayed by CHL animals. Asymptotic performance is used as an indirect measure of attention in children (Bargones et al., 1995), false alarm rate has been used as a proxy for sustained attention (Lin et al., 1999; Kanaka et al., 2008), and reaction time is associated with accuracy and task difficulty (Cattell, 1886; Saltzman and Garner, 1948; Buck, 1966; Luce and Green, 1972; Teichner and Krebs, 1972; Weissberg et al., 1990; Salthouse and Hedden, 2002). To the extent that these measures assess nonsensory factors, there was 
no indication of a difference between the control and $\mathrm{CHL}$ groups (Figs. 4, 5).

The duration of hearing loss is a key variable often correlated with the age of onset and may confound interpretation of the effect of age of onset. For prelingually deafened humans who receive a cochlear prosthesis, a longer duration of auditory deprivation is associated with poorer auditory perceptual skills, including speech comprehension (Tong et al., 1988; Busby et al., 1992, 1993; Schramm et al., 2002; Svirsky et al., 2004; McConkey Robbins et al., 2004; Niparko et al., 2010). A similar outcome has been reported for postlingually deafened cochlear implant listeners (Gantz et al., 1993; Blamey et al., 1996; Rubinstein et al., 1999). In apparent contrast, hearing loss at an earlier age and/or for a longer duration is associated with better speech recognition for a group of 20 subjects with severely elevated high-frequency thresholds (Seldran et al., 2011). Because most human subjects receive remediation of some sort (e.g., auditory prostheses, speech therapy), it is difficult to determine the influence of learning or acclimatization-driven neural plasticity mechanisms (Turner et al., 1996). Here, we demonstrate that juvenile-onset CHL impairs FM detection, even when compared with adult-onset CHL animals that are matched for duration of sensory deprivation.

Finally, it is possible that animals attended to small amplitude modulation (AM) in the stimulus. Using the speaker calibration, we calculated the maximum level change that would be expected for the average FM depth detection threshold values of each group, and compared this with published AM detection thresholds. For controls $(25 \mathrm{~Hz})$, the stimulus contained a $1.4 \mathrm{~dB}$ level change. This is smaller than the adult AM detection threshold (3.4 dB) calculated from Rosen et al. (2012), suggesting that controls did not use an AM cue. For P10 CHLs $(89 \mathrm{~Hz})$, the stimulus contained a $6.2 \mathrm{~dB}$ level change. This is larger than the P10 CHL AM detection threshold $(4.5 \mathrm{~dB})$ calculated from Rosen et al. (2012), suggesting that P10 CHLs could have used an AM cue. If CHL animals did exploit the intensity cues to assist in detecting the FM tone, then they may have even poorer FM depth thresholds than reported here. However, P10 CHL animals had access to the same acoustic information as the adult CHL animals, yet displayed a deficit in perception relative to adult CHL that cannot be attributed to non-sensory factors. When compared to normal-hearing adults, it remains possible that both CHL groups used sound level information to augment their FM detection performance.

\section{Relationship to neural consequences of conductive hearing loss}

By several measures, the effect of CHL on the CNS depends on age of onset. Bilateral CHL has a smaller affect on 2-deoxyglucose uptake, a measure of metabolic activity, when it is induced in adult compared with P21 or younger gerbils (Tucci et al., 1999). Similarly, unilateral CHL has a smaller affect on neural activity, as assessed by $\mathrm{Mn}^{2+}$-enhanced magnetic resonance imaging, when induced at P21 compared with P10 mice (Yu et al., 2005). However, unilateral CHL can produce both age-dependent and ageindependent effects in auditory cortex. Tonotopy is affected when CHL begins before P28, responses from the unmanipulated ear are augmented when CHL begins at P28, and responses from the manipulated ear are suppressed even when CHL begins in adulthood (Popescu and Polley, 2010). Furthermore, depending on the auditory processing metric under study, the effects due to hearing loss can display quite specific critical periods (Polley et al., 2013). It has been suggested that heightened sensitivity of the developing system to hearing loss is due to an extended period during which synapse formation and elimination is occurring in auditory cortex (Kral and Sharma, 2012). These neural findings are consistent with our result of poorer FM detection thresholds in both age groups, with a greater effect for animals with juvenileonset CHL (Fig. 2).

The large perceptual effect of adult CHL cannot be explained entirely by the cellular changes that occur following early onset CHL (Xu et al., 2007, 2010; Takesian et al., 2010). For example, CHL leads to a reduction in the strength of cortical inhibition when induced at P10, but not at P83 (Takesian et al., 2012). In contrast, the weaker inhibition that accompanies adult onset hearing loss may involve changes to GABA content and release (Bledsoe et al., 1995; Ling et al., 2005; Caspary et al., 2008). Therefore, our findings can serve to distinguish neural properties that display an early sensitive period and are more likely to differentiate the effects of juvenile hearing loss from those that are not sensitive to age of deprivation, and may explain the perceptual effect of adult-onset CHL.

\section{References}

Banai K, Sabin AT, Wright BA (2011) Separable developmental trajectories for the abilities to detect auditory amplitude and frequency modulation. Hear Res 280:219-227. CrossRef Medline

Bargones JY, Werner LA, Marean GC (1995) Infant psychometric functions for detection: Mechanisms of immature sensitivity. J Acoust Soc Am 98: 99-111. CrossRef Medline

Blamey P, Arndt P, Bergeron F, Bredberg G, Brimacombe J, Facer G, Larky J, Lindström B, Nedzelski J, Peterson A, Shipp D, Staller S, Whitford L (1996) Factors affecting auditory performance of postlinguistically deaf adults using cochlear implants. Audiol Neurootol 1:293-306. CrossRef Medline

Bledsoe SC Jr, Nagase S, Miller JM, Altschuler RA (1995) Deafness-induced plasticity in the mature central auditory system. Neuroreport 7:225-229. Medline

Buck L (1966) Reaction time as a measure of perceptual vigilance. Psychol Bull 65:291-304. CrossRef Medline

Busby PA, Tong YC, Clark GM (1992) Psychophysical studies using a multiple-electrode cochlear implant in patients who were deafened early in life. Audiology 31:95-111. CrossRef Medline

Busby PA, Tong YC, Clark GM (1993) The perception of temporal modulations by cochlear implant patients. J Acoust Soc Am 94:124-131. CrossRef Medline

Buss E, Hall JW 3rd, Grose JH (2004) Temporal fine-structure cues to speech and pure tone modulation in observers with sensorineural hearing loss. Ear Hear 25:242-250. CrossRef Medline

Caspary DM, Ling L, Turner JG, Hughes LF (2008) Inhibitory neurotransmission, plasticity and aging in the mammalian central auditory system. J Exp Biol 211:1781-1791. CrossRef Medline

Cattell JM (1886) The influence of the intensity of the stimulus on the length of the reaction time. Brain 8:512-515.

Chisolm TH, Willott JF, Lister JJ (2003) The aging auditory system: anatomic and physiologic changes and implications for rehabilitation. Int $J$ Audiol 42:2S3-2S10. Medline

Clements M, Kelly JB (1978) Auditory spatial responses of young guinea pigs (Cavia porcellus) during and after ear blocking. J Comp Physiol Psychol 92:34-44. CrossRef Medline

Demany L, Semal C (1989) Detection thresholds for sinusoidal frequency modulation. J Acoust Soc Am 85:1295-1301. CrossRef Medline

de Villers-Sidani E, Merzenich MM (2011) Lifelong plasticity in the rat auditory cortex: basic mechanisms and role of sensory experience. Prog Brain Res 191:119-131. CrossRef Medline

Erzurumlu RS, Gaspar P (2012) Development and critical period plasticity of the barrel cortex. Eur J Neurosci 35:1540-1553. CrossRef Medline

Espinosa JS, Stryker MP (2012) Development and plasticity of the primary visual cortex. Neuron 75:230-249. CrossRef Medline

Formby C, Sherlock LP, Gold SL (2003) Adaptive plasticity of loudness induced by chronic attenuation and enhancement of the acoustic background. J Acoust Soc Am 114:55-58. CrossRef Medline

Fründ I, Haenel NV, Wichmann FA (2011) Inference for psychometric functions in the presence of nonstationary behavior. J Vis 11:1-19. CrossRef Medline 
Gantz BJ, Woodworth GG, Knutson JF, Abbas PJ, Tyler RS (1993) Multivariate predictors of audiological success with multichannel cochlear implants. Ann Otol Rhinol Laryngol 102:909-916. Medline

Gray L, Kesser B, Cole E (2009) Understanding speech in noise after correction of congenital unilateral aural atresia: effects of age in the emergence of binaural squelch but not in use of head-shadow. Int J Pediatr Otorhinolaryngol 73:1281-1287. CrossRef Medline

Halliday L, Bishop DV (2006) Is poor frequency modulation detection linked to literacy problems? A comparison of specific reading disability and mild to moderate sensorineural hearing loss. Brain Lang 97:200-213. CrossRef Medline

Heffner HE, Heffner RS (1995) Conditioned avoidance. In: Methods in comparative psychoacoustics, Ed 1. (Klump GM, Dooling RJ, Fay RR, Stebbins WC, eds). Basel: Birkhäuser.

Hooks BM, Chen C (2007) Critical periods in the visual system: changing views for a model of experience-dependent plasticity. Neuron 56:312326. CrossRef Medline

Humes LE, Dubno JR, Gordon-Salant S, Lister JJ, Cacace AT, Cruickshanks KJ, Gates GA, Wilson RH, Wingfield A (2012) Central presbycusis: a review and evaluation of the evidence. J Am Acad Audiol 23:635-666. CrossRef Medline

Kanaka N, Matsuda T, Tomimoto Y, Noda Y, Matsushima E, Matsuura M, Kojima T (2008) Measurement of development of cognitive and attention functions in children using continuous performance test. Psychiatry Clin Neurosci 62:135-141. CrossRef Medline

Kelly JB, Cooke JE, Gilbride PC, Mitchell C, Zhang H (2006) Behavioral limits of auditory temporal resolution in the rat: amplitude modulation and duration discrimination. J Comp Psychol 120:98-105. CrossRef Medline

Keuroghlian AS, Knudsen EI (2007) Adaptive auditory plasticity in developing and adult animals. Prog Neurobiol 82:109-121. CrossRef Medline

King AJ, Parsons CH, Moore DR (2000) Plasticity in the neural coding of auditory space in the mammalian brain. Proc Natl Acad Sci U S A 97: 11821-11828. CrossRef Medline

Knudsen EI, Esterly SD, Knudsen PF (1984a) Monaural occlusion alters sound localization during a sensitive period in the barn owl. J Neurosci 4:1001-1011. Medline

Knudsen EI, Knudsen PF, Esterly SD (1984b) A critical period for the recovery of sound localization accuracy following monaural occlusion in the barn owl. J Neurosci 4:1012-1020. Medline

Kral A, Sharma A (2012) Developmental neuroplasticity after cochlear implantation. Trends Neurosci 35:111-122. CrossRef Medline

Lewis TL, Maurer D (2005) Multiple sensitive periods in human visual development: evidence from visually deprived children. Dev Psychobiol 46: 163-183. CrossRef Medline

Lin CC, Hsiao CK, Chen WJ (1999) Development of sustained attention assessed using the continuous performance test among children 6-15 years of age. J Abnorm Child Psychol 27:403-412. CrossRef Medline

Lin FR, Metter EJ, O'Brien RJ, Resnick SM, Zonderman AB, Ferrucci L (2011) Hearing loss and incident dementia. Arch Neurol 68:214-220. CrossRef Medline

Ling LL, Hughes LF, Caspary DM (2005) Age-related loss of the GABA synthetic enzyme glutamic acid decarboxylase in rat primary auditory cortex. Neuroscience 132:1103-1113. CrossRef Medline

LoLordo VM, Fairless JL (1985) Pavlovian conditioned inhibition: the literature since 1969. In: Information processing in animals (Miller RR, Spear NE, eds), pp 1-50. Hillsdale, NJ: Lawrence Erlbaum.

Long GR, Clark WW (1984) Detection of frequency and rate modulation by the chinchilla. J Acoust Soc Am 75:1184-1190. Medline

Luce RD, Green DM (1972) A neural timing theory for response times and the psychophysics of intensity. Psychol Rev 79:14-57. CrossRef Medline

McConkey Robbins A, Koch DB, Osberger MJ, Zimmerman-Phillips S, Kishon-Rabin L (2004) Effect of age at cochlear implantation on auditory skill development in infants and toddlers. Arch Otolaryngol Head Neck Surg 130:570-574. CrossRef Medline

Mogil JS (1999) The genetic mediation of individual differences in sensitivity to pain and its inhibition. Proc Natl Acad Sci U S A 96:7744-7751. CrossRef Medline

Moore BC, Sek A (1996) Detection of frequency modulation at low modulation rates: Evidence for a mechanism based on phase locking. J Acoust Soc Am 100:2320-2331. CrossRef Medline

Moore BC, Skrodzka E (2002) Detection of frequency modulation by hearing- impaired listeners: effects of carrier frequency, modulation rate, and added amplitude modulation. J Acoust Soc Am 111:327-335. CrossRef Medline

Moore BC, Wojtczak M, Vickers DA (1996) Effect of loudness recruitment on the perception of amplitude modulation. J Acoust Soc Am 100:481489. CrossRef

Moore DR, Hine JE, Jiang ZD, Matsuda H, Parsons CH, King AJ (1999) Conductive hearing loss produces a reversible binaural hearing impairment. J Neurosci 19:8704-8711. Medline

Munro KJ, Blount J (2009) Adaptive plasticity in brainstem of adult listeners following earplug-induced deprivation. J Acoust Soc Am 126:568571. CrossRef Medline

Niparko JK, Tobey EA, Thal DJ, Eisenberg LS, Wang NY, Quittner AL, Fink NE (2010) Spoken language development in children following cochlear implantation. JAMA 303:1498-1506. CrossRef Medline

Oxenham AJ, Bacon SP (2003) Cochlear compression: perceptual measures and implications for normal and impaired hearing. Ear Hear 24:352-366. CrossRef Medline

Parsons CH, Lanyon RG, Schnupp JW, King AJ (1999) Effects of altering spectral cues in infancy on horizontal and vertical sound localization by adult ferrets. J Neurophysiol 82:2294-2309. Medline

Pienkowski M, Eggermont JJ (2011) Cortical tonotopic map plasticity and behavior. Neurosci Biobehav Rev 35:2117-2128. CrossRef Medline

Polley DB, Thompson JH, Guo W (2013) Brief hearing loss disrupts binaural integration during two early critical periods of auditory cortex development. Nat Commun 4:2547. CrossRef Medline

Ponton CW, Eggermont JJ (2001) Of kittens and kids: altered cortical maturation following profound deafness and cochlear implant use. Audiol Neurootol 6:363-380. CrossRef Medline

Popescu MV, Polley DB (2010) Monaural deprivation disrupts development of binaural selectivity in auditory midbrain and cortex. Neuron 65:718-731. CrossRef Medline

Rosen MJ, Sarro EC, Kelly JB, Sanes DH (2012) Diminished behavioral and neural sensitivity to sound modulation is associated with moderate developmental hearing loss. PLoS One 7:e41514. CrossRef Medline

Rubinstein JT, Parkinson WS, Tyler RS, Gantz BJ (1999) Residual speech recognition and cochlear implant performance: effects of implantation criteria. Am J Otol 20:445-452. Medline

Salthouse TA, Hedden T (2002) Interpreting reaction time measures in between-group comparisons. J Clin Exp Neuropsychol 24:858-872. CrossRef Medline

Saltzman IJ, Garner WR (1948) Reaction time as a measure of span of attention. J Psychol 25:227-241. CrossRef Medline

Sarro EC, Sanes DH (2010) Prolonged maturation of auditory perception and learning in gerbils. Dev Neurobiol 70:636-648. CrossRef Medline

Scheiman MM, Hertle RW, Beck RW, Edwards AR, Birch E, Cotter SA, Crouch ER Jr, Cruz OA, Davitt BV, Donahue S, Holmes JM, Lyon DW, Repka MX, Sala NA, Silbert DI, Suh DW, Tamkins SM; Pediatric Eye Disease Investigator Group (2005) Randomized trial of treatment of amblyopia in children aged 7 to 17 years. Arch Ophthalmol 123:437-447. CrossRef Medline

Schramm D, Fitzpatrick E, Séguin C (2002) Cochlear implantation for adolescents and adults with prelinguistic deafness. Otol Neurotol 23:698 703. CrossRef Medline

Sek A (1994) Modulation detection thresholds and critical modulation frequency based on random amplitude and frequency changes. J Acoust Soc Jpn 15:67-75.

Seldran F, Gallego S, Micheyl C, Veuillet E, Truy E, Thai-Van H (2011) Relationship between age of hearing-loss onset, hearing-loss duration, and speech recognition in individuals with severe-to-profound high-frequency hearing loss. J Assoc Res Otolaryngol 12:519-534. CrossRef Medline

Sharma A, Dorman MF, Spahr AJ (2002) A sensitive period for the development of the central auditory system in children with cochlear implants: implications for age of implantation. Ear Hear 23:532-539. CrossRef Medline

Shower EG, Biddulph R (1931) Differential pitch sensitivity of the ear. J Acoust Soc Am 3:275-287.

Singh NC, Theunissen FE (2003) Modulation spectra of natural sounds and ethological theories of auditory processing. J Acoust Soc Am 114:33943411. CrossRef Medline

Svirsky MA, Teoh SW, Neuburger H (2004) Development of language and speech perception in congenitally, profoundly deaf children as a function of age at cochlear implantation. Audiol Neurootol 9:224-233. CrossRef Medline 
Syka J (2002) Plastic changes in the central auditory system after hearing loss, restoration of function, and during learning. Physiol Rev 82:601636. CrossRef Medline

Syka J (2010) The Fischer 344 rat as a model of presbycusis. Hear Res 264: 70-78. CrossRef Medline

Takesian AE, Kotak VC, Sanes DH (2010) Presynaptic GABAB receptors regulate experience-dependent development of inhibitory short-term plasticity. J Neurosci 30:2716-2727. CrossRef Medline

Takesian AE, Kotak VC, Sanes DH (2012) Age-dependent effect of hearing loss on cortical inhibitory synapse function. J Neurophysiol 107:937-947. CrossRef Medline

Teichner WH, Krebs MJ (1972) Laws of the simple visual reaction time. Psychol Rev 79:344-358. CrossRef Medline

Tong YC, Busby PA, Clark GM (1988) Perceptual studies on cochlear implant patients with early onset of profound hearing impairment prior to normal development of auditory, speech, and language skills. J Acoust Soc Am 84:951-962. CrossRef Medline

Tucci DL, Cant NB, Durham D (1999) Conductive hearing loss results in a decrease in central auditory system activity in the young gerbil. Laryngoscope 109:1359-1371. CrossRef Medline

Turner CW, Humes LE, Bentler RA, Cox RM (1996) A review of past research on changes in hearing aid benefit over time. Ear Hear 17:14S-25S. CrossRef Medline

Turner JG, Parrish JL, Zuiderveld L, Darr S, Hughes LF, Caspary DM, Idrez- begovic E, Canlon B (2013) Acoustic experience alters the aged auditory system. Ear Hear 34:151-159. CrossRef Medline

Wagner AR, Rescorla RA (1972) Inhibition in Pavlovian conditioning: application of a theory. In: Inhibition and learning (Boakes RA, Halliday S, eds), pp 301-316. New York: Academic.

Weissberg R, Ruff HA, Lawson KR (1990) The usefulness of reaction time tasks in studying attention and organization of behavior in young children. J Dev Behav Pediatr 11:59-64. Medline

Whitton JP, Polley DB (2011) Evaluating the perceptual and pathophysiological consequences of auditory deprivation in early postnatal life: a comparison of basic and clinical studies. J Assoc Res Otolaryngol 12:535-547. CrossRef Medline

Wilmington D, Gray L, Jahrsdoerfer R (1994) Binaural processing after corrected congenital unilateral conductive hearing loss. Hear Res 74:99-114. CrossRef Medline

Xu H, Kotak VC, Sanes DH (2007) Conductive hearing loss disrupts synaptic and spike adaptation in developing auditory cortex. J Neurosci 27: 9417-9426. CrossRef Medline

$\mathrm{Xu}$ H, Kotak VC, Sanes DH (2010) Normal hearing is required for the emergence of long-lasting inhibitory potentiation in cortex. J Neurosci 30:331341. CrossRef Medline

Yu X, Wadghiri YZ, Sanes DH, Turnbull DH (2005) In vivo auditory brain mapping in mice with Mn-enhanced MRI. Nat Neurosci 8:961-968. CrossRef Medline 